\title{
NOTA CRÍTICA AO INSTITUTO DA AÇÃO COLETIVA PASSIVA NO DIREITO BRASILEIRO
}

\section{CRITICAL NOTE ABOUT THE PASSIVE CLASS ACTION IN BRAZILIAN LAW}

Clayton Maranhão*

\begin{abstract}
Resumo: Analisa a figura da ação coletiva passiva, concluindo pela impossibilidade de qualquer ação coletiva que não tenha como escopo a tutela de interesses metaindividuais.
\end{abstract}

Palavras-chave: Ação coletiva passiva, Processo Civil Coletivo, Código Brasileiro de Processos Coletivos.

Abstract: It analyzes the figure of the passive class action, concluding for the impossibility of any class action that does not have as target the guardianship of metaindividuais interests.

Key- words: Passive class action, Collective Civil action, Brazilian code of Collective Processes.

\footnotetext{
* Mestre e Doutor em Direito pela UFPR. Professor de Direito Processual Civil em cursos de graduação e pós-graduação. Promotor de Justiça em Curitiba.
} 


\section{DO DESCABIMENTO DA AÇÃO COLETIVA PASSIVA NO DIREITO POSITIVO BRASILEIRO}

Problema que merece um aceno neste trabalho é o relativo ao cabimento, ou não, da chamada ação coletiva passiva no direito positivo brasileiro. Nos termos do parágrafo segundo do artigo $5^{\underline{a}} \mathrm{da}$ LACP, "fica facultado ao Poder Público e a outras associações legitimadas nos termos deste artigo habilitar-se como litisconsortes de 'qualquer' das partes". A redação do texto legal abre ensejo à discussão quanto ao cabimento, ou não, da ação coletiva passiva entre nós.

No direito comparado, Vincenzo Vigoriti (1979, p. 99-100) discorre que a experiência converge no sentido de que a iniciativa das demandas coletivas tem sido formulada pelos legitimados, jamais contra um interesse difuso ou coletivo cuja legitimidade eles detém, mas que, todavia, a hipótese de uma "ação coletiva passiva" contra um interesse metaindividual não pode ser aprioristicamente excluída. Vigoriti exemplifica com a "ação coletiva meramente declaratória, positiva ou negativa”, promovida por uma empresa ou por outros sujeitos de qualquer modo "interessados na eliminação de um estado de incerteza" sobre a legitimidade e adequação de um equipamento de depuração ou sobre a suficiência dos meios empregados na tutela da saúde de membros de uma determinada comunidade. Adverte que o cabimento de "ação coletiva passiva" para hipóteses similares é obviamente muito reduzida, contudo parece-lhe difícil uma exclusão absoluta. Prossegue afirmando que nos limitados e raros casos em que possa vir a ser admitida a "ação coletiva passiva", a questão que se põe é aquela de saber contra quem deva ser proposta. Se em face de todos os colegitimados (no caso do direito positivo brasileiro, o Ministério Público, as associações civis, as fundações, os sindicatos, os órgãos públicos despersonalizados e os demais entes da administração pública direta e indireta), ou em face de somente alguns dos co-legitimados (por exemplo, somente em face de uma associação de defesa ambiental de reconhecida militância na comarca ou circunscrição), mas, em caso de procedência, com eficácia erga omnes da coisa julgada material, impedindo a rediscussão da matéria, por exemplo, por parte do Ministério Público. 
Conclui Vigoriti, afirmando que a primeira solução é impossível, e que a segunda somente é viável se vier expressamente prevista em lei, o que, de iure constituto, não ocorre no direito brasileiro.

Portanto, a previsão isolada do parágrafo segundo do artigo $5^{\underline{a}}$ da LACP "não é", por si só, suficiente a que se tenha como cabível a "ação coletiva" passiva no direito positivo brasileiro, "assim entendida aquela que veicule pedido imediato de natureza declaratória contra um interesse difuso ou coletivo", isto é, uma ação coletiva "inversa" proposta pelo poluidor contra os entes exponenciais (MANCUSO, 1999, p. 212-213). ${ }^{1}$

Propostas, no entanto, já estão sendo esboçadas em tal sentido, como é o caso do já referido Código Modelo de Processos Coletivos para os Países Ibero-Americanos, em cujos artigos 31 a 34 formulase o cabimento de "ação coletiva passiva" em face de uma coletividade organizada ou que tenha represente adequado, cuja sentença de procedência terá qualidade de coisa julgada erga omnes, desde que se trate de interesse difuso ou coletivo, ressalvando-se os titulares de direitos individuais decorrentes de origem comum (homogêneos), os quais não ficarão cobertos pela coisa julgada, desde que promovam as respectivas ações individuais com o escopo de afastá-la de sua esfera jurídica. Pelos termos da proposta, o Ministério Público não seria legitimado passivo para esse tipo de ação coletiva, tendo por incumbência exclusiva e obrigatória a interveniência na relação processual (fiscal da lei).

Não se descarta que se for eventualmente acolhida a ação coletiva passiva no direito positivo brasileiro, dela venham abusar os

\footnotetext{
${ }^{1}$ Os exemplos dados por Rodolfo de Camargo Mancuso não se enquadrariam, propriamente, na concepção de ação coletiva passiva meramente declaratória. Quanto ao exemplo dado por esse autor da ação coletiva passiva proposta para impedir que uma empresa construa uma usina incineradora de lixo, embora os subsídios técnicos indiquem que tal solução é a melhor, somente seria enquadrável como tal se, uma vez pressuposta a sua previsão no ordenamento jurídico, fosse aforada pela empresa poluidora, no caso irresignada com recomendação expedida pelo Ministério Público ou no âmbito de inquérito civil público, mas de qualquer modo seria uma ação coletiva passiva flagrantemente abusiva, cujo decreto de carência seria inevitável por falta de interesse processual, na perspectiva da necessidade e da utilidade.
} 
poluidores, possibilidade essa aventada recentemente pela doutrina (GIDI, 2003). ${ }^{2}$

Considerando que há pesquisas recentes a respeito do assunto, objeto de candentes debates no meio acadêmico, com forte tendência para o acolhimento do instituto entre nós, cabe porém algumas considerações críticas quanto ao seu alcance.

\section{A PREVISÃO DO CABIMENTO DE AÇÃO COLETIVA PASSIVA NO ANTEPROJETO DE CÓDIGO BRASILEIRO DE PROCESSOS COLETIVOS}

Consta do artigo 36 do Anteprojeto de Código Brasileiro de Processos Coletivos que qualquer espécie de ação pode ser proposta contra uma coletividade organizada, desde que o bem jurídico a ser tutelado seja transindividual.

Pretende-se, por meio desse dispositivo projetado, a inserção no ordenamento jurídico brasileiro do instituto da ação coletiva passiva, por direta influência do direito norte-americano, onde é conhecido por defendant class action.

$\mathrm{Na}$ verdade, temos constatado que já têm sido ajuizadas algumas demandas com "pedido declaratório negativo" em face do Ministério Público, objetivando sentença e coisa julgada material a respeito de suposta inexistência de responsabilidade de agentes políticos detentores de mandato político, que invariavelmente estão sendo objeto de inquérito civil público instaurado para apuração da prática de atos de improbidade administrativa.

\footnotetext{
${ }^{2}$ Antonio Gidi, um dos defensores da ação coletiva passiva, há várias soluções possíveis para os diversos temas relativos às ações coletivas, "cada qual com suas vantagens, desvantagens e possibilidades de abuso". Note-se que os mesmos argumentos utilizados pela doutrina que adverte sobre os eventuais abusos da ação coletiva ativa serão também aplicáveis para eventuais abusos no manejo da ação coletiva passiva. Nesse sentido, Rogério Lauria Tucci. Ação civil pública: abusiva utilização pelo Ministério Público e distorção pelo Poder Judiciário. In: Aspectos polêmicos da ação civil pública (Coord.) Arnoldo Wald. São Paulo: Saraiva, 2003, p. 355-392; Kazuo Watanabe. Demandas coletivas e os problemas emergentes da práxis forense. In: As garantias do cidadão na Justiça (Coord.) Min. Sálvio de Figueiredo Teixeira. São Paulo: Saraiva, 1993, p. 185-196.
} 
Muito embora não seja de nosso conhecimento que alguma dessas aventuras forenses - típicos juízos de jactância, como se dizia antes da elaboração das teorias que deram autonomia ao direito de ação processual - tenham logrado julgamento de procedência, é fato que apenas não são rotuladas como ação coletiva passiva, pois na sua essência assim podem ser consideradas.

Vê-se, desde logo, que acaso o Anteprojeto de Código Brasileiro de Processos Coletivos venha a ser aprovado, instituindo-se como útil e adequado o manejo de ação coletiva passiva em face da coletividade organizada, mesmo assim consideramos que faltará interesse de agir naquelas demandas com pedido declaratório negativo preponderante.

Não descartamos o cabimento eventual da defendant class action em outras hipóteses, das quais se pode tirar como exemplo o aforamento de ação coletiva inibitória em face de ente representante de fornecedores de determinado produto ou serviço, objetivando a não aplicação de cláusula contratual geral, que contenha critério abusivo de reajuste, em futuros contratos de adesão.

Portanto, identificamos como útil e adequada a ação coletiva passiva naqueles casos - clássicos, diga-se de passagem - em que haja intensa conflituosidade interna, vale dizer, entre os dois grupos envolvidos, quando então haverá de ser tomada uma escolha política entre um dos interesses coletivamente organizados (ex. a desapropriação de uma área para construção de um aeroporto supersônico e os interesses dos moradores; a instalação de uma indústria metalúrgica, gerando empregos e impostos e os interesses dos moradores, e assim por diante) (MANCUSO, 2004).

Como se percebe, podemos estar apenas diante de um novo rótulo da demanda coletiva, tendo como pano de fundo velhas questões. Se assim for, poderemos aceitar o neologismo, sabidamente irrelevante na perspectiva da técnica processual.

O que não aceitaremos jamais é o abuso processual das ações coletivas, seja qual for o nome que se dê a ela. 


\section{REFERÊNCIAS}

GIDI, A. Código de Processo Civil Coletivo. Um modelo para países de direito escrito. Revista de Processo n. 111, jul./set./2003, p. 192-207.

MANCUSO, R. de C. Ação civil pública. Ed. RT. 6.ํe․, 1999.

. Interesses Difusos. 6. ed. São Paulo: Revista dos Tribunais, 2004.

VIGORITI, V. Interesse Colettivi e Processo. La legittimazione ad agire. Milão: Giuffrè, 1979. 